\title{
CARÁTER COMUNITÁRIO DA CONSTITUIÇÃO FEDERAL DE 1988 SOB A PERSPECTIVA DOS INSTRUMENTOS DE CONCRETIZAÇÃO DAS NORMAS CONSTITUCIONAIS: MANDADO DE INJUNÇÃO E AÇÃO DIRETA DE INCONSTITUCIONALIDADE POR OMISSÃO - INSTRUMENTOS QUE CONFEREM EFICÁCIA AOS DIREITOS FUNDAMENTAIS
}

\author{
COMMUNITY CHARACTER OF THE FEDERAL \\ CONSTITUTION OF 1988 UNDER THE PERSPECTIVE OF \\ INSTRUMENTS OF ACHIEVEMENT OF CONSTITUTIONAL \\ STANDARDS: WRIT OF ORDER AND DIRECT ACTION BY \\ OMISSION OF UNCONSTITUTIONALITY - INSTRUMENTS \\ THAT GIVE EFFECTIVE TO FUNDAMENTAL RIGHTS
}

Luciana Ferreira Mello*

\begin{abstract}
"Das utopias. Se as coisas são inatingíveis, não há motivo para não querê-las, que tristes seriam os caminhos, sem a presença distante das estrelas! (QUINTANA, 2006, p. 959)
\end{abstract}

SUMÁRIO: Introdução, 1. Principais correntes teóricas acerca da justiça: os liberais contratualistas; libertários, críticos deliberativos e comunitaristas; 2 Constitucionalismo Comunitário brasileiro; 3 - Análise dos instrumentos de concretização constitucional - Mandado de Injunção e Ação Direta de Inconstitucionalidade por omissão; Conclusão.

RESUMO: A proposta do presente artigo é apresentar as cinco principais correntes acerca da justiça presentes no debate teórico no âmbito da filosofia política, iniciando pelos liberais contratualistas através da análise da obra "Uma teoria de Justiça" de John Rawls. Em seguida serão apresentados os demais autores que apresentam críticas à obra de Ralws e desenvolvem suas teorias a partir dela, são eles os libertários através da análise de Robert Nozick; posteriormente, os ensinamentos de Jürgen Habermas a

\footnotetext{
* Possui graduação em Direito - Faculdades Integradas do Brasil (2009), especialização em Direito Aplicado pela EMAP (2010), mestranda em Direito Constitucional pela Unibrasil (2013) Atualmente, leciona na FAPAR - Faculdade Paranaense - a disciplina de Direito Constitucional. Atua como advogada nas áreas trabalhista, cível e família. Leciona Direitos Humanos em curso preparatório para Concursos Públicos.
} 
respeito da corrente crítica deliberativa, será apresentado o panorama do republicanismo Philip Pettit, e, por último, mediante a análise da obra de Michael Sandel apresentar em síntese a doutrina comunitarista. Na sequência, busca-se, lançando mão dos estudos de Gisele Guimarães Cittadino apresentar a doutrina comunitarista brasileira apontando alguns aspectos que demonstram o caráter comunitarista da Constituição Federal de 1988, principalmente, com ênfase na preocupação com a concretização dos direitos fundamentais previstos no texto constitucional. Por fim, será realizada uma breve análise dos instrumentos de concretização constitucional, partindo das propostas constituintes referentes ao Mandado de Injunção e à ADIN por omissão, instrumentos que identificam o caráter comunitarista da Carta Magna vigente.

Palavras-chave: teorias da justiça, liberais, libertários, crítico deliberativos, comunitaristas, constituição federal 1988, mandado de injunção, adi por omissão, concretização, direitos fundamentais.

ABSTRACT: The purpose of this article is to present the four main currents about justice present in the theoretical debate within political philosophy, namely: the liberal contractualist by analyzing the work "A Theory of Justice" by John Rawls, in sequence, the other authors who have criticisms of this work and develop their theories from it; libertarians through analysis of Robert Nozick; present the teachings of Jürgen Habermas about the critical current deliberative, and, finally, through the analysis of work of Michael Sandel present in brief the communitarian doctrine. Further, looking up, making use of Gisele Guimarães Cittadino studies, present the communitarian doctrine Brazilian pointing out some aspects that demonstrate the communitarian character of the Constitution of 1988, mainly with emphasis on concern for the realization of fundamental rights provided in the Constitution. Finally, there will be a brief constitutional instruments of implementation, from analysis of the constituent proposals for the Writ of Injunction and ADIN default, instruments that identify the communitarian character of the Constitution in force.

Keywords: theories of justice, liberal, libertarian, critical deliberative communitarians, federal constitution 1988, injunction, ADI default, achievement

\section{INTRODUÇÃO}

O presente artigo tem a intenção de fundamentar o caráter comunitário da Constituição de 1988 com base na previsão constitucional dos instrumentos de concretização das normas constitucionais: o Mandado de Injunção e a Ação Declaratória de Inconstitucionalidade por Omissão, doravante denominada no decorrer do presente estudo de ADIO.

Salienta-se que a Constituição Federal de 1988 é classificada como analítica ${ }^{1}$ e dirigente ${ }^{2}$. Tal classificação, por si só, faz com que a

\footnotetext{
1 “Também chamadas de prolixas ou extensas, que aquelas que são formadas por textos longos, minuciosos, dotados além de disposições normativas de caráter principiológico,
} 
determinação de qual ou quais das correntes acima citadas tal documento adota seja tarefa complexa, pois possui um dos mais extensos textos normativos.

Tendo em mente o caráter analítico ${ }^{3}$ da Constituição Federal de 1988, neste estudo, seria tarefa demasiadamente ampla analisá-la como um todo, e, assim incompatível com os limites deste artigo, por isso, objetiva-se identificar a corrente precipuamente anotada, sem a pretensão de afirmar que esta seja a única, pois, conforme restará comprovado o texto constitucional é extenso. Desta forma, o presente estudo defende que este é apenas um viés da Constituição que, devido a sua extensão, pode apresentar outras influências.

Promulgada em 5 de outubro de 1988, a Carta Magna recebeu a alcunha de "Constituição Cidadã", , por um de seus idealizadores, Ulysses Guimarães, presidente da Assembléia Nacional Constituinte. Salutar trazer um trecho do discurso do ilustre congressista, proferido na data da promulgação:

de muitas regras mais ou menos estritas. A constituição do tipo analítico como é o caso da Constituição Federal de 1988, além de retirar da disposição de legislador ordinário um conjunto bem maior de matérias, em geral, são bem mais frequentemente reformadas, pois quanto mais regras contemplam, mais se torna difícil a atualização da constituição mediante o processo legislativo ordinário e a interpretação." (SARLET, 2012, p. 212)

2 O termo Dirigente significa que o poder constituinte, ao redigir o texto constitucional, "dirige" a atuação futura dos órgãos governamentais, tendo em vista os programas que metas que a constituição estabeleceu em seu texto. Logo, para que uma constituição possa ser classificada de dirigente, é necessário que esta contenha em seu texto normas programáticas. Assim, socialmente falando, tendo em vista a supremacia da constitucional, e a importância de seu texto para o ordenamento jurídico pátrio, ao menos na teoria, inserir no texto constitucional metas sociais, seria uma garantia de que essas metas sejam realmente alcançadas. (SARLET, 2012, p. 212)

3 De acordo com José Afonso da Silva: "O Constituinte (...) rejeitou a chamada constituição sintética, que é a constituição negativa, porque construtora apenas da liberdade-negativa ou liberdade-impedimento, oposta à autoridade, modelo de constituição que, às vezes, se chama de constituição-garantia (ou constituição quadro). A função garantia não foi só preservada como até ampliada na nova constituição não como mera garantia do existente ou como simples garantia das liberdades negativas ou liberdades-limites. Assumiu o texto a característica de constituição-dirigente, enquanto define fins e programas de ação futura." (SILVA, 1989, p. 6)

${ }^{4}$ Tal alcunha deveu-se à restituição da ampla cidadania e dos direitos fundamentais, após duas décadas de restrições e cerceamentos no exercício destes e de supressão de liberdades públicas em geral, bem como ao regate da noção de Estado Social de Direito. (BESTER, 2005, p. 12) 
Tipograficamente é hierarquizada a precedência e a preeminência do homem, colocando-o no umbral da Constituição e catalogando-lhe o número não superado, só no art. $5^{\circ}$, de 77 incisos e 104 dispositivos. Não lhe bastou, porém, defendê-lo contra os abusos originários do Estado e de outras procedências. Introduziu o homem no Estado, fazendo-o credor de direito e serviços, cobráveis inclusive com o Mandado de Injunção. Tem substância popular e cristã o título que a consagra: 'A Constituição Cidadã'. (SILVA, 1989, p. 6)

Assim, em uma concepção formal a Constituição Federal de 1988, contempla o verdadeiro significado da Lei Fundamental de Bonn ${ }^{5}$, pois coloca em posição de destaque os direitos fundamentais que estão dispostos em seus primeiros capítulos. Ademais se destaca sua relevância, no sentido de que foi a responsável por instituir um Estado Democrático de Direito.

Paulo Bonavides, por sua vez, afirma que a Constituição Federal de 1988, promoveu um grande avanço, quando inseriu em seu texto três grandes garantias, quais sejam: o Mandado de Injunção, o Mandado de Segurança Coletivo e a Ação de Inconstitucionalidade por Omissão ${ }^{6}$. Pois, desta maneira, logrou êxito em resolver, nas palavras deste autor, ao que chama de "o grande problema do Direito Constitucional" (BONAVIDES, 2002, p. 372-373), que seria o de como juridicizar ${ }^{7}$ o Estado Social.

Assim, a Constituição Federal de 1988 deu um passo à frente no que tange à garantia dos direitos fundamentais, pois não obstante elencar um vasto rol de direitos foi além, e inseriu em seu texto instrumentos que

\footnotetext{
${ }^{5}$ Semelhante à Constituição Federal Alemã.

6 "O mandado de injunção tem, portanto, por finalidade realizar concretamente, em favor do impetrante, o direito, a liberdade ou a prerrogativa, sempre que a falta da norma regulamentadora torne inviável o seu exercício. Não visa obter a regulamentação prevista na norma constitucional. Não é função do mandado de injunção pedir a expedição de norma regulamentadora, pois ele não é sucedâneo da Ação de Inconstitucionalidade por omissão (art. 103, §2 $2^{\circ}$ )" (SILVA, 1989, p. 397).

${ }^{7}$ A judicialização decorre do modelo analítico de Constituição e do sistema abrangente de controle de constitucionalidade adotados no Brasil, que permitem que discussões de largo alcance político e moral sejam trazidas sob a forma de ações judiciais. Assim, a judicialização não decorre da vontade do judiciário, mas do constituinte. (BARROSO, 2009, p. 344.)
} 
possibilitam ao indivíduo assumir seu papel ativo na postulação de seus direitos constitucionalmente previstos.

Tendo em vista o sopro de esperança alçado com a promulgação da Constituição Federal de 1988, que vem recheada de direitos e boas intenções sob a influência da doutrina comunitarista, o que se visa no presente estudo é apontar os instrumentos de concretização dos direitos fundamentais, sendo o Mandado de Injunção e a Ação Declaratória de Inconstitucionalidade por omissão, como grandes evidências do caráter comunitarista da Constituição Federal de 1988.

Assim, estudo se desenvolve da seguinte maneira: num primeiro momento, serão apresentadas, em apertada síntese, as quatro principais correntes a respeito da teoria de justiça existentes no debate teórico no âmbito da filosofia política, representadas pelas doutrinas liberal, libertária, crítico deliberativa, republicanista e comunitarista. Tais correntes apresentam diversos autores partidários de cada uma, tendo em vista a exiguidade do espaço, e ciente das particularidades de cada um, serão abordados os principais autores de cada uma delas.

Por esta razão ao tratar sobre os liberais contratualistas será lançado mão dos ensinamentos de John Rawls ${ }^{8}$ que inaugurou os debates, em 1971, com a obra: "Uma teoria de justiça". No que toca aos libertários tomar-se-á como norte os ensinamentos de Robert Nozick ${ }^{9}$ em sua obra: "Anarquia Estado e Utopia”, publicada em 1974. Já no que concerne aos críticos deliberativos, serão utilizados os ensinamentos de Jürgen Habermas ${ }^{10}$, utilizando sua obra: "A inclusão do outro", datada de 1992; no republicanismo lançar-se-á mão dos ensinamentos de Philiph Pettit $^{11}$. Com relação especificamente ao comunitarismo, será analisada uma vertente mais "amena" com base nas doutrinas de: Michael Sandel ${ }^{12}$ com fundamento, precipuamente, na obra: "Liberalismo e os limites da justiça", publicada em 1998.

\footnotetext{
${ }^{8}$ John RAWLS foi professor de filosofia da Universidade de Harvard (1921-2002).

${ }^{9}$ Robert Nozick era Filósofo político e foi professor da Universidade de Harvard (19382002).

${ }^{10}$ Jürgen Habermas é filósofo e sociólogo alemão (1929).

11 Philip Noel Pettit (1945) é um filósofo e teórico político irlandês. Professor da Laurence Rockefeller University e Professor de Política e Valores Humanos na Universidade de Princeton.

${ }^{12}$ Michael J. Sandel é considerado um dos mais influentes pensadores da atual Filosofia Política em sua versão comunitarista. Professor há mais de quinze anos em Cambridge, onde leciona precisamente a disciplina Filosofia Política.
} 
O seguinte tópico se ocupará de trazer em linhas gerais a síntese dos postulados da doutrina comunitarista nacional. Para cumprir esta finalidade serão trazidos os ensinamentos oriundos dos estudos de Gisele Cittadino a respeito da doutrina comunitarista nacional: tais como José Afonso da Silva, Paulo Bonavides, Fabio Konder Comparato e Dalmo de Abreu Dalari, que condensam os ensinamentos comunitaristas brasileiro. Evidenciando a preocupação com a concretização da nova ordem constitucional que se instaurou em 1988.

O último tópico se encarregará de demonstrar como foram as discussões a respeito da concretização das normas constitucionais que culminaram no advento do Mandado de Injunção e da Ação Direta de Inconstitucionalidade por Omissão, novidades inseridas em nosso ordenamento jurídico através da nova constituição.

Com o auxílio dos ensinamentos de Gisele Guimarães Cittadino depreendem-se vários instrumentos que evidenciam um caráter comunitarista da Constituição Federal. Dentre eles serão abordados com mais profundidade o Mandado de Injunção e a ADI por omissão.

Tais instrumentos adentraram no ordenamento jurídico em 1988 com a promulgação da Constituição Federal em um período de redemocratização do país, por isso, o último tópico está dedicado a abordar como se realizou a inserção destes instrumentos na Constituição por meio da apresentação das propostas constituintes.

Entender as teorias político filosóficas que abordam o tema é de fundamental importância para tentar formar um conceito de o que seja a justa e de como pode ser organizada uma sociedade justa. Assim, estudar o passado e as propostas da assembleia constituinte de 1987 é útil para compreender como os instrumentos que visam à efetividade das normas constitucionalmente previstas foram abordados em sede constituinte. Saber como eles foram idealizados é importante para aferir se, e, como estes instrumentos têm atingido as finalidades almejadas.

Muito pugna-se pela justiça e por uma sociedade justa, mas pouco se sabe acerca desses conceitos, e, ainda, pouco se sabe sobre os instrumentos que a própria Constituição prevê para efetivação da justiça prevista em seu bojo. Neste sentido, o presente artigo tem a intenção de clarificar o entendimento e ampliar o horizonte das percepções a respeito da justiça e de uma sociedade justa, por meio da abordagem das teorias que tratam sobre estes conceitos e dos instrumentos constitucionalmente previstos para efetivação das normas constitucionais. 
Em consonância com os ensinamentos da doutrina comunitarista restará evidente que a participação popular ativa é de fundamental importância para que uma sociedade justa aliada a um ordenamento jurídico adequado possam ser alcançados. No decorrer do presente estudo serão apresentadas as teorias acerca da justiça, com ênfase na doutrina comunitarista, que na esfera doutrinária nacional pugna pela concretização das normas constitucionais contidas numa constituição que representa um movimento de retorno ao direito, após logos anos de ditadura militar, sendo que o Mandado de Injunção e a Ação Direta de Inconstitucionalidade por Omissão, novidades inseridas pela nova constituição, representam instrumentos que prometem essa concretização e respeito às previsões constitucionais.

\section{PRINCIPAIS TEORIAS ACERCA DA JUSTIÇA: OS LIBERAIS; OS LIBERTÁRIOS, OS CRÍTICO DELIBERATIVOS, OS REPUBLICANOS E OS COMUNITARISTAS.}

Este tópico se encarrega de apresentar como as teorias acerca da justiça se desenvolveram no cenário internacional até culminar na doutrina comunitarista foco central do presente estudo.

A partir dos anos 1980 os debates acerca das relações entre ética, direito e política tornaram-se mais profundas e passaram a ocupar um lugar privilegiado no campo da filosofia política sobre um ideal de justiça, uma sociedade justa e sobre a criação de um ordenamento jurídico adequado a esta sociedade. Tais debates iniciaram com a proposta de teoria de justiça de Rawls, e continuam com as demais correntes que buscam, mediante a crítica deste posicionamento apresentar propostas alternativas. (CITTADINO, 2004, p. 2-3)

Rawls $^{13}$ é considerado representante do liberalismo contratualista, pois, como contratualista ${ }^{14}$ busca apresentar uma versão de contrato

\footnotetext{
${ }^{13}$ Salienta-se, primeiramente, que RAWLS não é o único representante do liberalismo contratualista, no entanto, foi ele quem inaugurou as discussões a respeito das relações entre justiça. Ética e sociedade, sendo Dworkin, um dos adeptos desta corrente. Ademais, salienta-se que o presente estudo não tem como finalidade apresentar a totalidade desta teoria, pois para tanto o autor utilizou mais de trezentas páginas. Logo, tendo em vista a exiguidade do espaço, intenta-se de maneira sucinta apresentar as linhas gerais desta corrente com a finalidade de apresentar o contraponto das teorias que se seguiram e as críticas formuladas. Este aviso também se aplica para as demais correntes que serão brevemente abordadas posteriormente.
} 
social para justificar a autoridade estatal. É onde se apresenta $o$ véu da ignorância, pois afirma que os indivíduos prestes a "assinar o contrato" que forma a sociedade e a eleger os princípios norteadores, não podendo elegê-los com base em suas aspirações pessoais, para que possam fazê-lo da maneira mais impessoal possível, terão que se utilizar do véu da ignorância e, assim, decidir somente com base em seu sendo de justiça.

De acordo com Rawls ao determinar quais os princípios que devem reger uma sociedade seus componente não poderiam ser parciais levando em consideração suas condições individuais, tais como classe social, nível de ensino e etnia, pois estas influências prejudicariam a eleição dos princípios, daí a importância de um instrumento que os livrasse dessas influências: 'o véu da ignorância'.

Além disso, Rawls apresenta em sua obra dois princípios de justiça capacitados para garantir a liberdade e a igualdade, sendo que o primeiro refere-se a um esquema no qual os direitos e liberdades básicas sejam compatíveis com as liberdades de todos, neste esquema, as liberdades políticas iguais, e, somente estas, devem ser garantidas por seu justo valor; no que tange ao segundo princípio, as desigualdades sociais e econômicas devem satisfazer duas condições: uma, devem ter relação com os postos e posições abertos para todos em condições de plena igualdade e equidade de oportunidades, e, segunda, devem resultar no maior benefício dos que detém menos riquezas dentre os componentes da sociedade. Destes princípios depreende-se a primazia dos direitos individuais sobre os demais. (RAWLS, 2000, p. 31.)

Para Rawls a legitimidade das regras, está justamente, no fato de que todos que aderiram ao pacto ou contrato também auxiliaram na elaboração das regras e têm como intenção uma sociedade justa e organizada.

Assim, o autor constrói uma dimensão monológica da concepção da justiça como imparcialidade (CITTADINO, 2004, p. 106.). Esta concepção monológica e individualista demonstra-se presente em todas as fases apresentas por Rawls, na primeira, é mera somatória das

\footnotetext{
${ }^{14}$ Correntes teóricas que intentam explicar como a sociedade se formou e sobre a legitimidade do poder estatal, ou seja, o que levou os indivíduos a se associar e organizar por meio da sociedade. Existem várias versões para explicar esse fenômeno e justificar a autoridade estatal. Dentre as obras estão: "O Leviatã" - 1651 - Thomaz Hobbes, "Segundo tratado sobre Direito Civil" - 1690 - de John Locke e "O contrato social" - 1762 - de Jean-Jacques Rousseau.
} 
concepções individuais (decisão que cada componente toma sob o véu da ignorância) que vai determinar os princípios de justiça a serem a dotados, ou seja, não utiliza a deliberação como forma de construção da decisão coletiva.

No momento seguinte verifica-se a necessidade de colocar em prática os princípios anteriormente definidos, seria como se cada um justificasse a aplicação a sua maneira, com base em seus juízos morais individuais. Na sequência, ocorre um processo de observação mútua, no qual os sujeitos se observam e compartilham uma visão de mundo razoável, o que não significa que haja debate público. (RAWLS, 2000, p. 140)

Nozick, representante da corrente dos libertários (também conhecidos como liberais clássicos), por sua vez, é partidário de uma noção de justiça que expressa a necessidade de, no máximo, um estado mínimo que teria o condão, apenas, de "proteger todos os cidadãos contra a violência, o roubo, a fraude e o não cumprimento dos contratos" (RAWLS, 2000, p. 26).

Os direitos protegidos seriam, apenas, o direito de propriedade e o direito de liberdade, além disso Nozick pugna pelo estabelecimento de um estatuto de restrição destes direitos. Tendo em vista a proposta de um Estado Mínimo enfrenta o problema de: como evitar o anarquismo da seguinte maneira: "em primeiro lugar, as pessoas e as organizações atuariam segundo seu próprio interesse racional; em segundo lugar: respeitariam os interesses dos outros, não os infringindo ou, pelo menos compensando-os, se ocorresse uma infração”. (NOZICK, 1991, p. 31)

Com relação à emergência do Estado Nozick apresenta uma forma muito semelhante à contratualista: "Primeira etapa: em vez dos inconvenientes do estado de natureza, os indivíduos formam ou aderem a organizações de proteção.", que seriam formadas por famílias e amigos; na etapa seguinte a organização torna-se dominante em cada região; na terceira etapa: a organização protege os "clientes" contra a defesa dos sujeitos independentes; na última etapa: a organização deve indenizar os independentes da situação desvantajosa. (NOZICK, 1991, p. 38)

Pode-se concluir dos ensinamentos destas etapas que o Estado Mínimo de Nozick fornece proteção de todos os membros e detém o monopólio da força para tanto, pois impede os indivíduos de defenderem seus direitos contra os membros.

A principal crítica que Nozick tece contra Rawls está situada no que concerne ao direito de propriedade, pois enquanto aquele entende o 
direito de propriedade "como se as coisas fossem maná caído do céu" (KUKATHAS, et al., 1995, p. 110), para Rawls a justiça está na distribuição destes bens.

Phillip Pettit, republicano, sintetiza a crítica de Nozick em duas objeções principais: a primeira a de que Rawls teria errado ao partir do princípio de que os bens vieram ao mundo sem serem de propriedade de ninguém, e que estariam à espera de uma justa distribuição baseada numa concepção de justiça; a segunda que o estado nos moldes construídos por Rawls promoveria muitas intervenções nas questões individuais. E, ainda, segundo Phillip Pettit, o grande feito de Nozick foi fornecer um esboço de um alternativa da corrente libertária, mas não o de lograr êxito em minar a teoria de Ralws. (KUKATHAS, et al., 1995, p. 110)

As críticas de Habermas a respeito da teoria de Rawls estão relacionadas ao procedimento adotado, pois segundo ele, este teria esvaziado a racionalidade. Para Habermas, partidário de uma teoria reconstrutivista, também designado de crítico deliberativo ${ }^{15}$, o objetivo é reconstruir a dimensão moral que se insere no âmbito das interações comunicativas, isto é, na intersubjetividade. (HABERMAS, 1989, p. 31)

Habermas desenvolve três principais críticas contra a teoria da justiça formulada por Rawls, a primeira está relacionada à condição primitiva idealizada por Rawls, e a forma como tenta colocar os indivíduos em condição de imparcialidade; em segundo lugar, critica a forma como desenvolveu sua teoria sem realizar a separação entre questões de fundamentação de questões de aceitabilidade, deixando transparecer o desejo de conquistar a neutralidade em relação a sua concepção de justiça ao preço de uma reivindicação cognitiva de validação; por consequência, a terceira crítica, de que esta estratégia resulta, segundo Habermas, na construção de um Estado que subordina o princípio da legitimação democrática a direitos fundamentais. (HABERMAS, 2002, p. 63)

De maneira muito respeitosa, Habermas ${ }^{16}$, de acordo com o trecho acima, critica a tese de Rawls muito mais em virtude da forma do que em

\footnotetext{
${ }^{15}$ Cittadino, adota esta classificação em razão da teoria de Habermas estar relacionada à ampla deliberação pública de que demanda a formação racional da vontade. (CITTADINO, 2004, p, 2)

16 Habermas concebe a razão comunicativa - e a ação comunicativa ou seja, a comunicação livre, racional e crítica - como alternativa à razão instrumental e superação da razão iluminista - "aprisionada" pela lógica instrumental, que encobre a dominação. Ao pretender a recuperação do conteúdo emancipatório do projeto moderno, no fundo,
} 
razão do conteúdo de sua teoria por ter sido desenvolvida dentro do paradigma da consciência. Em breve síntese, para este crítico é através da linguagem comunicativa que os indivíduos podem interagir e chegar ao senso comum a respeito de determinado assunto, e não individualmente como propõe Rawls.

Para que seja possível entender a fundamentação da crítica habermasiana, lança-se mão do conceito de paradigma desenvolvido por Tomas Kuhn e explicado por Ludwig, no qual paradigma é a racionalidade considerada como padrão teórico e hegemônico, que determinada comunidade em determinado momento, utiliza na busca de compreensões e soluções. (LUDWIG, 2006, p. 24-25.)

Para além do conceito de paradigma frisa-se que, historicamente, existem quatro grandes grupos paradigmáticos na filosofia, sendo eles: o paradigma do ser, da consciência, do agir comunicativo e da vida concreta de cada sujeito. (LUDWIG, 2006, p. 14)

Habermas elabora um quadro teórico entre um paradigma que se esgota, o paradigma da consciência, e outro que se projeta, o paradigma da comunicação, ou agir comunicativo. Ambos trabalham com a relação entre o sujeito e o objeto. Enquanto o paradigma da consciência (LUDWIG, 2006, p. 100) é a perspectiva do sujeito capaz de conhecer o objeto e através do autoconhecimento tornando-se apto a dominar a natureza. (LUDWIG, 2006, p. 103)

$\mathrm{Na}$ elaboração do paradigma da ação comunicativa, como um novo paradigma a ser estabelecido, Habermas confere ao sujeito a tarefa de não apenas se entender com o objeto, mas o de se entender como os demais sujeitos, sobre o que significa e conhecer e dominar os objetos. $\mathrm{O}$ enfoque não está mais na autocompreensão, mas na intersubjetividade. (LUDWIG, 2006, p. 104)

Habermas, ainda, propõe um modelo de processo democrático, o procedimentalista, que se baseia nas condições de comunicação que possibilitam a existência de resultados racionais oriundos do processo político através do modo deliberativo.

Habermas está preocupado com o restabelecimento dos vínculos entre socialismo e democracia.

Segundo o autor, duas esferas coexistem na sociedade: o sistema e o mundo da vida. $\mathrm{O}$ sistema refere-se à 'reprodução material', regida pela lógica instrumental (adequação de meios a fins), incorporada nas relações hierárquicas (poder político) e de intercâmbio (economia). (HABERMAS, 1989, p. 31.) 
Após a explicação sobre a crítica de Habermas a Rawls, percebese que ele propõem a solução através de um discurso racional, que consubstancia-se em toda tentativa de entendimento sobre pretensões de validade problemáticas, na medida em que ele se realiza sob condições da comunicação que permitem o movimento livre de temas e contribuições, informações e argumentos no interior de um espaço público. (HABERMAS, 1997, p. 113 a 168 e 297 a 353)

Ou seja, a crítica está no fato de Rawls ter utilizado um paradigma filosófico já ultrapassado, pois a solução que se encontra mediante a consciência individual foi superada pelo discurso racional intersubjetivo, portanto, a ação comunicativa substitui a reflexão solitária, que é anterior à fala, pela ação do discurso comunicativo. (LUDWIG, 2006, p.105.)

Representante do comunitarismo, Michael Sandel analisa se a maneira hipotética apresentada por Rawls para abordar a questão da justiça seria a mais adequada. Em sua análise identifica que um acordo moral, mesmo que entre duas pessoas, apesar de haver a aquiescência de ambas não significa que, por si só, tal acordo seja justo, é necessário um referencial de justiça.

A constituição, por exemplo, mas até mesmo a Constituição, pelo fato de ter sido ratificada pelo povo, isto não significa que ela seja justa, pois apesar de inúmeras virtudes a Constituição Americana de 1987 foi eivada pelo vício da escravatura. Ou seja, para Sandel, nenhum contrato social ou constituição, por mais aceitação que tenha e mais representativa que seja, garante que seus termos de cooperação social sejam justos. Para ele moralidade nada tem a ver com consenso. (SANDEL, 2010, p. 172 205.)

De acordo com Sandel, que para Rawls a justiça seria a primeira virtude das instituições sociais, mas para que isso possa ser verdade, segundo Sandel, é necessário uniformidade no comportamento e que cada um possa ser independente de seus interesses particulares, que é o que define nossas obrigações e interesses particulares. E, ainda, que o recurso do "véu da ignorância" é inviável para tentar afastar os interesses individuais quando da eleição dos princípios a serem seguidos. (KUKATHAS, et al., 1995, p. 129)

E, ainda, para Sandel vê razão nos ensinamentos de Aristóteles no que se refere a Teoria de um ordenamento jurídico justo. Segundo ele antes que se possa definir os direitos de um povo, ou se questionar sobre a natureza de uma possível constituição ideal é necessário, primeiramente, determinar a natureza do modo de vida mais apreciável. 
Apesar de todas as críticas que tece em face da teoria de Rawls, Sandel, por fim, reconhece que: "Quer sua teoria de justiça venha a ser aceita, quer não, ela representa a proposta mais convincente de uma sociedade equânime já produzida pela filosofia política americana" (SANDEL, 2010, p. 10). Salienta-se que o autor está se referindo especificamente no que tange ao aspecto da igualdade, e não com relação à teoria de Rawls em sua totalidade.

Em linhas gerais, no âmbito internacional foi desta maneira que se desenvolveram as teorias da justiça até culminar no pensamento comunitário, acerca de qual seria o ordenamento jurídico mais adequado a uma sociedade justa que integrasse a ética, o direito e a comunidade.

Cittadino sintetiza as quatro correntes de pensamento acerca da justiça da seguinte maneira: os liberais e libertários privilegiam os direitos fundamentais por conferirem prioridade à autonomia privada; para Habermas - o crítico deliberativo - a autonomia privada e pública, associadas à auto-realização ética, são pressupostos mútuos, os assuntos da sociedade devem ser associados a um amplo debate público, não havendo hierarquia entre os dois tipos de direitos; já os comunitários conferem prioridade maior à soberania popular, enquanto participação ativa dos cidadãos nos interesses públicos, de modo que, somente pode ser instituído um direito legítimo com a garantia não apenas dos direitos subjetivos, mas também através da participação, que por consequência, possibilita maior concretização dos direitos previstos. (CITTADINO, 2004, p. 7)

Este primeiro tópico encarregou-se de apresentar o quadro internacional no qual as discussões a respeito da teoria da justiça se desenvolveu. $\mathrm{O}$ próximo tópico se encarregará de demonstrar como o pensamento comunitário estrangeiro influenciou na doutrina pátria, apontando os principais postulados da vertente brasileira do comunitarismo e, adicionalmente, identificar quais os instrumentos evidenciam esse viés comunitário da Constituição Federal de 1988.

\section{O CONSTITUCIONALISMO COMUNITÁRIO BRASILEIRO}

O movimento comunitário teve início na doutrina estrangeira, primeiramente na Alemanha, posteriormente, influenciando o constitucionalismo português, espanhol e brasileiro. O constitucionalismo alemão traduz a noção de que a constituição indica compromissos com determinados ideais compartilhados, acredita na 
concretização da carta magna através da participação comunitária nos assuntos públicos. (CITTADINO, 2004, p. 226)

Gisele Cittadino aponta como representantes do constitucionalismo comunitário em Portugal: José Joaquim Gomes Canotilho, Jorge Miranda e José Carlos Vieira de Andrade, já na Espanha, elencam-se: Pablo Lucas Verdu e Antonio Enrique Pérez Luño. Cittadino sintetiza o pensamento comunitário na crença de que a constituição incorpora os valores de uma comunidade histórica concreta, e de que há uma intersecção entre a realidade constitucional (realidade dos fatos) e a constituição, sendo a constituição o documento que reúne os valores jurídicos básicos acolhidos pela sociedade. (CITTADINO, 2004, p.226)

Como se objetiva neste estudo identificar o caráter comunitário da Constituição Federal de 1988 é imprescindível identificar a doutrina nacional a respeito. Dentre os autores que CITTADINO elenca como comunitaristas estão: José Afonso da Silva (SILVA, 1989), Carlos Roberto Siqueira de Castro (SIQUEIRA CASTRO, 1995), Paulo Bonavides (BONAVIDES, 2002), Fabio Konder Comparato, Eduardo Seabra Fagundes, Dalmo de Abreu Dallari, Joaquim de Arruda Falcão Neto, os quais revelaram o compromisso constitucional através de diversos textos e artigos. Tais autores recusavam o constitucionalismo liberal, marcado pela defesa do individualismo racional, elegendo, um constitucionalismo societário e comunitário. (CITTADINO, 2004, p. 15)

Carlos Roberto Siqueira Castro, ao definir constitucionalismo societário comunitário, determina que a estrutura normativa da constituição deve envolver um conjunto de valores e, que, estes devem ser compartilhados pela comunidade política. (SIQUEIRA CASTRO, 1995)

José Afonso da Silva, por sua vez, afirma que algumas condutas humanas passam a ser valoradas pelas comunidades historicamente e, tornam-se fundamento para o modo de agir em comunidade, que se reflete nos elementos constitucionais de determinado grupo social, que se revelam no trabalho constituinte de elaboração da constituição. Seria como se a constituição refletisse os valores compartilhados pela sociedade. (SILVA, 1989, p. 31)

Retomando a fundamentação dos comunitaristas brasileiros, aponta-se que este constitucionalismo está calcado no binômio dignidade humana - solidariedade social, ultrapassando a concepção de direitos subjetivos, para dar lugar às liberdades positivas, limitando e 
condicionando a esfera individual em prol do coletivo. De modo que os direitos fundamentais não mais sejam pensados numa perspectiva individual, mas coletiva. Assim, exatamente, por rejeitar a concepção individual, adota-se o termo direitos fundamentais do homem que confere direitos e garantias iguais para todos. (CITTADINO, 2004, p. 17)

Deste modo, os direitos fundamentais são entendidos como valores. Ao mesmo tempo, estes valores constituem o núcleo básico do ordenamento e funcionam como critério interpretativo; são metas a serem alcançadas pelo Estado. (CITTADINO, 2004, p. 18)

Identifica-se um prisma comunitarista no constitucionalismo brasileiro, podendo ser apontados como argumento teórico o fato de que os direitos fundamentais positivados constitucionalmente possuem uma validação comunitária, pois pertencem à consciência ético-jurídica daquela comunidade. Como o princípio da dignidade da pessoa humana é um conceito aberto, alarga o leque de interpretes que possam preencher seu conteúdo por meio da participação político jurídica por via da democracia participativa.

Esta abertura de intérpretes resulta na concretização da constituição e garante a efetividade deste sistema constitucional e dos direitos por ele assegurados. Além disso, "a adoção de uma ordem constitucional concreta de valores; a existência de um conjunto de instrumentos processuais adequados a exercício da autonomia pública dos cidadãos seja, enfim, quando atribui um papel preponderantemente político ao Supremo Tribunal Federal. (CITTADINO, 2004, p. 10)

Promulgada em 5 de outubro de 1988, a Carta Magna recebeu a alcunha de "Constituição Cidadã", por um de seus idealizadores, Ulysses Guimarães, presidente da Assembleia Nacional Constituinte: Introduziu o homem no Estado, fazendo-o credor de direito e serviços, cobráveis inclusive com o Mandado de Injunção. Tem substância popular e cristã o título que a consagra: 'A Constituição Cidadã'. (CITTADINO, 2004, p. 10)

Esta constituição é repleta de direitos, que possuem conceitos vagos e imprecisos o que demanda interpretação para seu preenchimento. Para que se possa alcançar a concretização da ordem constitucional e a efetividade de suas normas, mecanismos de controle são necessários. Os institutos constitucionalmente previstos para controle são o mandado de injunção e a ação declaratória de inconstitucionalidade por omissão.

Assim, mediante a identificação da influência da doutrina constitucional comunitária sobre os estudiosos que auxiliaram em grande 
parte a elaboração do texto constitucional na década de 80 , bem como, mediante a correlação entre os pressupostos da doutrina comunitária e alguns instrumentos previstos na Constituição Federal de 1988, depreende-se as características acima denotam o viés comunitário desta constituição.

Como síntese deste tópico extrai-se que, apesar da ausência de uma Assembleia Constituinte exclusiva para a elaboração do texto constitucional, houve, além do amplo debate travado entre diversos segmentos da sociedade, a enorme influencia dos autores comunitaristas brasileiros, os quais sofreram forte influência do comunitarismo estrangeiro, seja ele alemão, português (socialismo) ou espanhol que assumem um conjunto específico de valores.

A doutrina comunitarista brasileira, tendo em vista, o período de abreviação de direitos ocasionado pelo regime militar pelo qual o Brasil passou na década de 80, desenvolveu sua doutrina baseada na necessidade de maior participação popular e no desejo de uma força concretizadora das normas constitucionais. Estes desejos se refletiram no texto constitucional, que desde os anteprojetos previa instrumentos para o controle da omissão estatal e concretização das normas constitucionais.

O próximo capítulo se encarregará de demonstrar como o assunto da concretização das normas constitucionais foi abordado nos projetos apresentados para a composição do texto constitucional.

\section{INSTRUMENTOS DE CONCRETIZAÇÃO CONSTITUCIONAL: MANDADO DE INJUNÇÃO E A AÇÃO DECLARATÓRIA DE INCONSTITUCIONALIDADE POR OMISSÃO - INSTRUMENTOS QUE EVIDENCIAM O ASPECTO COMUNITÁRIO DO CONSTITUCIONALISMO BRASILEIRO}

Motivo de grande avanço e de louvor à Constituição Federal de 1988, deve-se ao fato de que esta não somente se limitou a prever direitos, mas preocupou-se em prever meios para que os cidadãos pudessem garanti-los. A Carta Magna vigente prevê dois instrumentos que visam assegurar a eficácia e a aplicabilidade de todas as normas instituidoras de direitos e garantias fundamentais.

O Mandado de Injunção, inserido no ordenamento jurídico pátrio em 1988, está previsto no art. $5^{\circ}$, LXXI, consubstancia-se em instrumento que torna todas as normas constitucionais potencialmente aplicáveis, sua 
função é fazer valer um direito previsto na norma constitucional, cujo exercício é inviabilizado pela inércia legislativa.

Já a Ação Direita de Inconstitucionalidade por Omissão, também inserida no ordenamento jurídico brasileiro em 1988, encontra respaldo no art. 103 da Carta Magna vigente. Diferentemente do Mandado de Injunção, a Ação Direita de Inconstitucionalidade por Omissão tem por finalidade apenas dar ciência ao órgão omisso, e, em se tratando de omissão administrativa há a fixação do prazo de trinta dias para sanar a omissão.

A professora Gisela Maria Bester cita, ainda, um terceiro meio disponível com vistas a sanar a não efetivação das normas constitucionais, a iniciativa legislativa popular. A novidade nessa temática, segundo a autora, é a criação das Comissões de Legislação Participativa (CLP), tais comissões aprofundam a democracia participativa e aumentam o exercício da cidadania. (BESTER, 2005, p. 145)

De acordo com o disposto no artigo $5^{\circ}$, LXXI, da Constituição Federal: "Conceder-se-á mandado de injunção sempre que a falta de norma regulamentadora torne inviável o exercício dos direitos e liberdades constitucionais e das prerrogativas inerentes à nacionalidade, à soberania e à cidadania".

Alguns autores trazem possíveis conceituações para o referido instituto, os quais serão citados a seguir, começando pelo conceito de Marcelo Figueiredo: "Mandado de injunção á a ação constitucional posta à disposição de qualquer pessoa física ou jurídica, apta à tutela de direito individual, coletivo ou difuso, toda vez que houver falta de regulamentação de direitos infraconstitucional, que obstaculize a fruição." (FIGUEIREDO, 1991, p. 33)

Os debates que ocorreram na doutrina estrangeira quer seja ela alemã, quer seja norte-americana, influenciaram sobremaneira o pensamento constitucional brasileiro e estavam profundamente centradas no tema referente à concretização da constituição. (CITTADINO, 2004, p. 10) Por esta razão, o presente estudo abordará neste tópico final, especificamente, como se deram as propostas constituintes relacionadas ao Mandado de Injunção e a ADI por omissão, que afirmam o caráter comunitário da Constituição Federal.

De acordo com o que foi apresentado nos tópicos anteriores, o caráter comunitário esta evidenciado pelo arcabouço valorativo 
representado pelo amplo rol principiológico previsto, pela existência de instrumentos que visam à concretização das normas constitucionais e pelo papel hermenêutico conferido ao Supremo Tribunal Federal na Constituição de 1988.

Não é suficiente a mera previsão de inúmeros direitos e princípios sem que estes sejam efetivados, por isso é de fundamental importância instrumentos que controlem as omissões estatais no que tange aos direitos constitucionalmente previstos. Motivo de grande avanço e de louvor à Constituição Federal de 1988 deve-se ao fato de que esta não somente se limitou a prever direitos, mas preocupou-se em prever meios para que os cidadãos pudessem garanti-los, ou seja, concretizá-los. (SALGADO, 2005, p. 113-121)

O Mandado de Injunção, foi inserido no ordenamento jurídico pátrio em 1988, está previsto no art. 5, LXXI, consubstancia-se em instrumento que torna algumas normas constitucionais potencialmente aplicáveis, sua função é fazer valer um direito previsto na norma constitucional, cujo exercício é inviabilizado pela inércia legislativa.

Já a Ação Direita de Inconstitucionalidade por Omissão, também inserida no ordenamento jurídico brasileiro em 1988, encontra respaldo no art. 103 da Carta Magna vigente. Diferentemente do Mandado de Injunção, a Ação Direita de Inconstitucionalidade por Omissão tem por finalidade apenas dar ciência ao órgão omisso, e, em se tratando de omissão administrativa há a fixação do prazo de trinta dias para sanar a omissão.

No período de elaboração do texto constitucional, a Comissão de Estudos Constitucionais foi integrada pelos representantes do constitucionalismo comunitário brasileiro, sendo presidida por Afonso Arinos assessorado por Carlos Roberto Siqueira Castro e Ana Lucia Lyra Tavares. Esta comissão ficou responsável por elaborar estudos e apresentar um anteprojeto de Constituição.

É de fundamental importância salientar que a Comissão iniciou seus trabalhos tomando por base o anteprojeto de Constituição elaborado por José Afonso da Silva, que, de acordo com Cittadino, apesar de rejeitar esta nomenclatura, é considerado um dos mais respeitáveis comunitários nacionais. (CITTADINO, 2004, p. 10)

Primeiramente, no que se refere ao Mandado de Injunção, analisando o documento Uma proposta de constituição elaborado por José Afonso da Silva, verifica-se que não há menção expressa a este instrumento em sua proposta. No entanto, no artigo 14, cujo título é: 
eficácia dos direitos e garantias, identifica-se um possível embrião do instituto, dada a importância do documento histórico faz-se a citação direta da previsão:

Art. 14. Eficácia dos direitos e garantias.

As normas constitucionais relativas aos direitos e garantias são diretamente aplicáveis e vinculam as entidades públicas e privadas.

Incumbe aos poderes públicos promover as condições para que a igualdade e a liberdade do indivíduo sejam reais e efetivas, removendo os obstáculos de ordem econômica e social que impeçam o pleno desenvolvimento da pessoa humana e a participação de todos os trabalhadores na organização política, econômica, social e cultural do país. (SILVA, sem data, p. 110)

Analisando a proposta da Comissão Arinos, ainda, referente ao Mandado de Injunção, o parágrafo $1^{\circ}$ do artigo 10:

Artigo 10. Os direitos e garantias constantes desta Constituição têm aplicação imediata.

$1^{\circ}$. Na falta ou na omissão da lei prevista para discipliná-la, o juiz decidirá o caso, de modo a atingir os fins da norma constitucional. (SILVA, sem data, p. 5)

Ambos os projetos não preveem expressamente o instituto do Mandado de Injunção, não da forma como a redação final da Constituição Federal, em seu artigo 50, inc. LXXI: “conceder-se-á mandado de injunção sempre que a falta de norma regulamentadora torne inviável o exercício dos direitos e liberdades constitucionais e das prerrogativas inerentes à nacionalidade, à soberania e à cidadania". No entanto, viabilizam sua aceitação e também demonstram a preocupação com a eficácia das normas constitucionais. Sendo assim o objeto deste instrumento é limitado.

Já no que tange à Ação Declaratória de Inconstitucionalidade por Omissão, esta vinha expressamente prevista no artigo 189 do Anteprojeto de José Afonso da Silva, veja-se:

Artigo 189 - Inconstitucionalidades

1. A inconstitucionalidade pode ser ação ou por omissão 
3. Verifica-se a inconstitucionalidade por omissão nos casos em que não sejam praticados atos legislativos ou executivos requeridos para tornar plenamente aplicáveis normas constitucionais. (SILVA, sem data, 6) seguinte:

O parágrafo $2^{\circ}$, do artigo 10 da Comissão Arinos previa o

Art. 10.Os direitos e garantias constantes desta Constituição têm aplicação imediata.

2. Verificando a inexistência ou omissão da lei, inviabilizando a plenitude de eficácia de direitos e garantias asseguradas nesta Constituição, o Supremo Tribunal Federal recomendará a edição da norma que venha a suprir a lacuna. (SILVA, sem data, p. 110)

Neste sentido, tanto o anteprojeto de José Afonso da Silva como o da Comissão Arinos, previam expressamente o instituto da Ação Declaratória de Inconstitucionalidade por Omissão, tendo em vista a preocupação com a efetividade e concretização das normas constitucionais.

Especificamente, com relação à proposta da Comissão Arinos, esta autorizaria o juiz não a legislar, pois seria inconstitucional por afrontar a tripartição de poderes, mas a resolver o caso concreto caso não encontrasse no ordenamento jurídico norma que fosse aplicável à lide.

Mediante a análise dos projetos citados, verifica-se que desde a fase das discussões a respeito do texto que a constituição adotaria estava premente a preocupação com a concretização da constituição. As propostas citadas apresentam-se como embriões dos institutos promissores que hoje se encontram inseridos no ordenamento jurídico através da Constituição Federal de 1988.

Tais instrumentos são expressão da preocupação da doutrina comunitarista com a efetividade da constituição. O Mandado de Injunção, em especial, constitui-se oportunidade para que a população participe ativamente na vida pública da comunidade e evitem que a constituição torne-se mero pedaço de papel (LASSALE, 1985), letra morta.

No entanto, até idos de 2000, a visão do referido instituto não era das melhores, para Barroso, era inegável que o referido instituto não tinha logrado êxito em atingir às expectativas sobre ele lançadas, veja-se: 
Decorridos mais de doze anos de vigência da Constituição, é inegável que o mandado de injunção não atendeu, de modo significativo, às expectativas criadas com sua introdução. A principal causa de tal frustração de propósitos tem sido identificada na posição adotada pelo Supremo Tribunal Federal, na linha do precedentes assentado no julgamento de MI no 107-3-DF. (BARROSO, 2009, p. 117)

O precedente supra citado externa o entendimento do Supremo Tribunal Federal que esposa o posicionamento de que o mandado de injunção teria natureza mandamental. No entanto, o que fez com que o instituto fosse levado ao descrédito, seria o fato de que sua finalidade seria de meramente declarar a omissão, com a simples ciência do órgão omisso para que adote as providências necessárias.

Este posicionamento fez com que Barroso denominasse o instituto de "Mandado de injunção: o que foi sem nunca ter sido" $"$. Ora, se esta fosse, realmente, a finalidade prevista para o instituto pelo constituinte originário, sequer o teria criado, pois é esta a finalidade da ação de inconstitucionalidade por omissão.

Após receber severas críticas da doutrina em razão de seu posicionamento acima citado, o Supremo Tribunal, paulatinamente amenizou a rigidez de seu posicionamento, que se consolidou com a decisão proferida no MI no 284-3, posicionando-se da seguinte forma: i) admitiu converter uma norma constitucional de eficácia limitada em norma de eficácia plena; ii) considerou o mandado de injunção para obter regulamentação de qualquer direito previsto na Constituição.

No entanto, apesar de haver progredido em seu posicionamento, não autorizava que o tribunal suprisse qualquer lacuna, apenas autorizava a auto-aplicabilidade da norma de eficácia limitada, nos termos de regulamentação posterior. Deste modo, não se exigia do judiciário uma atuação no sentido de integrar a ordem jurídica, ou inovar no direito positivo.

\footnotetext{
17 Ainda, de acordo como entendimento de Barroso em 2006: "No contexto atual do constitucionalismo brasileiro, o mandado de injunção tornou-se uma desnecessidade, havendo alternativa teórica e prática de muito maior eficiência”. (BARROSO, 2009, p.112). Note-se que este posicionamento foi perfilado pelo autor na $2^{\mathrm{a}}$ edição de seu livro cujo título é $\mathrm{O}$ controle de constitucionalidade no direito brasileiro. Mas, que, no entanto, em sua última edição como se verá a seguir, o autor altera radicalmente seu posicionamento.
} 
Assunto especial referente ao tema de omissão legislativa é a questão do direito de greve do servidor público. No ano de 2006, no mandado de injunção ${ }^{\circ}$ 20, que teve como Relator o Ministro Celso de Mello, firmou-se entendimento que o direito de greve dos servidores públicos constituía norma de eficácia limitada, portanto, desprovida de auto-aplicabilidade.

Deste modo, sempre que o STF era chamado a se manifestar a este respeito, decidia-se unicamente pela necessidade da edição da norma reclamada, sem admitir a concretização direta da norma prevista constitucionalmente.

No entanto, em sessão de 7 de junho de 2002, foi proposta revisão parcial do entendimento adotado até o momento pelo STF. Nesta ocasião, o Ministro Eros Grau recomendou a adoção de uma "solução normativa e concretizadora" para a omissão em tela. Veja-se, trecho do voto do Ministro Eros Grau:

Neste contexto, é de se concluir que não se pode considerar simplesmente que a satisfação do exercício do direito de greve dos servidores públicos civis deva ficar a bel-prazer do juízo de oportunidade e conveniência do Poder Legislativo.

Estamos diante de uma situação jurídica que, desde a promulgação da Carta Federal de 1988 (ou seja, há mais de 17 anos), remanesce sem qualquer alteração. Isto é, mesmo com as modificações implementadas pela Emenda n ${ }^{\circ}$ 19/98 quanto à exigência de lei ordinária específica, o direito de greve dos servidores públicos ainda não recebeu $o$ tratamento legislativo minimamente satisfatório para garantir o exercício dessa prerrogativa em consonância com o s imperativos constitucionais.

Por essa razão, não estou a defender aqui a assunção do papel de legislador positivo pelo Supremo Tribunal Federal. Pelo contrário, enfatizo tão-somente que, tendo em vista as imperiosas balizas constitucionais que demandam a concretização do direito de greve a tosos os trabalhadores, este Tribunal não pode se abster de reconhecer que, assim como se estabelece o controle judicial sobre a atividade do legislador, é possível atuar também nos casos de inatividade ou omissão do Legislativo. (MENDES, 2009, p. 12661267)

Com a alteração sugerida pelo Ministro Eros Grau, verifica-se que este posicionamento demonstra-se como efetiva garantia de proteção 
judicial efetiva que não pode ser negligenciada na vivência democrática de um Estado de Democrático de Direito.

Deste modo, o Supremo Tribunal Federal abandonou a orientação inicialmente perfilhada no sentido de estar limitada à declaração da existência da mora legislativa para a edição da norma reguladora específica, passou, sem assumir compromisso como o exercício de uma típica atividade, a aceitar a possibilidade de uma regulamentação provisória pelo judiciário.

Mediante a verificação da evolução do pensamento político depreende-se que o Estado evoluiu de um "não fazer" sob a égide do liberalismo, para o patamar de garantidor sob a égide de um Estado Democrático de Direito, o qual exige a atividade legislativa para determinados direitos constitucionalmente previstos.

Deste modo, não se pode admitir que os destinatários da norma sejam privados do exercício de direitos constitucionalmente previstos, em razão da mora em legislar dos órgãos a quem a Constituição Federal determinou tal competência. Isto seria deixar de conferir eficácia aos Direitos Fundamentais constitucionalmente previsto, seria negar aos cidadãos o exercício de tais direitos.

Exatamente para coibir as omissões inconstitucionais que o constituinte de 1988 previu dois instrumentos distintos, a ação direta de inconstitucionalidade por omissão e o mandado de injunção, cujas diferenças foram oportunamente abordadas.

No entanto, verificou-se que durante longo período o mandado de injunção foi tido como instrumento inútil ou, quando muito, como instrumento que dependia de legislação infraconstitucional para ser aplicado. No entanto, apesar de ser alvo de críticas e desconfiança logo após a promulgação da Constituição Federal de 1988, o mandado de injunção logrou êxito em sua aplicabilidade com o advento das teorias concretistas.

O objetivo do presente estudo não é indicar qual das teorias concretistas é a mais adequada para atingir a finalidade do mandado de injunção, mas apesar salientar que, independentemente de se adotar a teoria concretista geral ou a mitigada, o simples fato haver uma evolução e o abandono da teoria não concretista fez com que o mandado de injunção tivesse a devida atenção no Poder Judiciário pátrio.

"Mas, o grande problema do Direito Constitucional de nossa época está, ao nosso ver, em como juridicizar o 
Estado Social, como estabelecer e inaugurar novas técnicas e institutos processuais para garantir os direitos sociais básicos a fim de fazê-los efetivos.

Por esse aspecto muito avançou o Estado Social da Carta de 1988, com o mandado de injunção, o mandado de segurança coletivo e a inconstitucionalidade por omissão. $\mathrm{O}$ Estado social brasileiro é, portanto, de terceira geração, em face desses aperfeiçoamentos temos: um Estado que não concede apenas direitos sociais básicos, mas os garante" (BONAVIDES, 2002, 373)

Deste modo, com respaldo em Paulo Bonavides, pode-se concluir que, o fato de o mandado de injunção ter verdadeiramente renascido com a adoção da teoria concretista é de fundamental importância para a garantia do indivíduo frente a omissão legislativa.

A utilização do Mandado de Injunção e da Ação Declaratória de Inconstitucionalidade por Omissão evidencia o caráter emancipatório do texto constitucional, proporcionado pela filtragem constitucional (SCHIER, 1999), pela qual transformações sociais podem ser realizadas evitando, assim, a perda da eficácia dos direitos constitucionalmente previstos.

E, ainda, muito mais que caráter emancipatório, o manejo destes instrumentos transparecem o viés comunitário da constituição de 1988, e a preocupação não apenas com a previsão de direitos fundamentais, mas a preocupação com sua concretização e efetividade destes direitos.

\section{CONCLUSÃO}

De tudo o que foi apresentado verifica-se que as discussões iniciadas por Rawls na década de 80, acerca de uma teoria da justiça que envolve uma sociedade justa e um ordenamento jurídico a ela adequado que, após inúmeras críticas que ensejaram propostas alternativas a sua teoria culminaram na doutrina comunitarista.

Os debates comunitaristas tiveram início, na Alemanha influenciando a doutrina espanhola e portuguesa, e, consequentemente, a brasileira. Em síntese, demonstrou-se que a doutrina comunitarista confere primazia à participação popular e preocupa-se com a concretização das normas constitucionais.

Quando da elaboração das propostas constitucionais, na década de 80, o pensamento comunitário influenciou sobremaneira na confecção 
dos pré-projetos constituintes, pois boa parte de seus idealizadores era partidário da doutrina comunitarista. (CITTADINO, 2004, p. 103)

Desta influência comunitarista resultou a preocupação com a concretização das normas constitucionais, o que era mais do que compreensível pelo fato de o país estar deixando um regime totalitário marcado pelo domínio militar não havendo sentido idealizar uma constituição repleta de direitos, mas ausente de mecanismos que pudessem colocá-los em prática.

Como frutos das discussões constituintes a respeito da efetividade das normas constitucionais resultaram o Mandado de Injunção e a Ação Declaratória de Inconstitucionalidade por Omissão que, apesar de suas especificidades e diversas características, constituíam instrumentos que prometiam dar maior efetividade às normas constitucionalmente previstas.

Como primeira conclusão, extrai-se que a atuação da doutrina comunitarista influenciou de maneira positiva na elaboração dos textos constitucionais, pois resultou, dentre outros, no advento de dois instrumentos que visam à concretização das normas constitucionais.

Uma conclusão mais geral que pode ser retirada do presente estudo é a de que, para que se possa alcançar uma sociedade justa é necessária a participação popular na confecção e no controle dos mecanismos responsáveis pela elaboração e manutenção do ordenamento jurídico.

Neste sentido, a Constituição Federal de 1988 é promissora no sentido de que além de prever inúmeros direitos e princípios fundamentais, também oferece estes instrumentos de incentivo ao controle de sua efetividade, conferindo importante papel à participação popular, não apenas através do Mandado de Injunção e da Ação Direta de Inconstitucionalidade por Omissão, mas prevê também a possibilidade de iniciativa popular de leis, bem como, hipóteses de plebiscito e referendo.

\section{REFERÊNCIAS}

BARROSO, Luis Roberto. 2009. O Controle de Constitucionalidade no Direito Brasileiro. São Paulo : Saraiva, 2009. 4. ed. 
BESTER, Gisela Maria. 2005. BESTER, Gisela Maria. Direito Constitucional, Fundamentos Teóricos. Vol I, São Paulo: Manole. 2005. São Paulo : Manole, 2005. Vol 1.

BONAVIDES, Paulo. 2002. Curso de Direito Constitucional. São Paulo : Malheiros, 2002. 12 ed.. . 2009. Do estado liberal ao estado social. São Paulo :

Malheiros, 2009.

BONAVIDES, Paulo. Do Estado Liberal ao Estado Social. 9. ed. São Paulo: Malheiros, 2009.

. Curso de direito constitucional. 12. ed. São Paulo: Malheiros, 2002.

CITTADINO, Gisele Guimarães. Pluralismo, direito e justiça distributiva: Elementos da Filosofia Constitucional Contemporânea. 3. ed. Rio de Janeiro: Editora Lumen Juris, 2004.

FIGUEIREDO, Marcelo. 1991. Mandado de injunção e inconstitucionalidade por omissão. São Paulo : RT, 1991.

HABERMAS, Jürgen. A inclusão do outro. [1992] Tradução de SPERBER. George, e SOETHE, Paulo Astor, São Paulo: Loyola, 2002.

. Consciência Moral e Agir Comunicativo. Rio de Janeiro: Tempo Brasileiro, 1989.

Direito e democracia: entre facticidade e validade. Rio de Janeiro: Tempo Brasileiro, 1997.

KUKATHAS, Chandran e PETTIT, Philip. RAWLS: "Uma Teoria da Justiça" e os seus críticos. Lisboa: Gradiva, 1995.

LASSALE, Ferdinand. O que é uma constituição? 2. Ed. São Paulo: Kairós, 1985. 
LUDWIG, Celso Luiz. Para uma filosofia jurídica da libertação: Paradigmas da filosofia, filosofia da libertação e direito alternativo. Florianópolis: Conceito Editorial, 2006.

MENDES, Gilmar Ferreira. 2009. Curso de Direito Constitucional. São Paulo : Saraiva, 2009. 4.ed.

NOZICK, Robert. Anarquia, Estado e Utopia [1974] Tradução de JUNGMANN. Ruy. Rio de Janeiro: Jorge Zahar Editor, 1991.

QUINTANA, Mario. Poesia Completa. Rio de Janeiro: Editora Nova Aguiar, 2006.

RAWLS, John. Uma teoria de Justiça [1971] 1. ed. 2a Tiragem. Tradução de PISETTA. Almiro e ESTEVES. Lenita M R, São Paulo: Martins Fontes, 2000.

SALGADO, Eneida Desiree. Tijolo por tijolo em um desenho (quase) lógico: vinte anos de construção do projeto democrático brasileiro. Curitiba, 244 f. Dissertação (Mestrado em Direito) Setor de Ciências Jurídicas, Universidade Federal do Paraná.

SANDEL. Michael J. Liberalismo e os limites da Justiça. [1998] Trad. PACHECO DO AMARAL. Carlos Eduardo. Coleção Textos Universitários. Cidade: 2010.

Justiça o que é fazer a coisa certa. Rio de Janeiro: Civilização Brasileira, 2012.

SARLET, Ingo Wolfgang. Curso de Direito Constitucional. São Paulo: Editora Revista dos Tribunais, 2012.

SCHIER, Paulo Ricardo. Filtragem Constitucional: Construindo uma nova dogmática jurídica. Porto Alegre: Sergio Antonio Fabris Editor, 1999.

SILVA, José Afonso da. Curso de Direito Constitucional Positivo, São Paulo: 1989. 
Uma proposta de Constituição. Inédito, sem data.

SIQUEIRA CASTRO. Carlos Roberto de. A constituição Aberta e a Atualidade dos Direitos Fundamentais do Homem. Rio de Janeiro. Tese (concurso para o professor Titular), 1995. 